\title{
ОБРАЗ СОКРАТА В ФИЛОСОФИИ ИОГАННА АВГУСТА ЭБЕРХАРДА
}

\section{К.В. Райхерт}

Немецкий философ, теолог и классический филолог Иоганн Август Эберхард (1739-1809) известен как один из учителей Фридриха Даниэля Эрнста Шлейермахера (1768-1834), как ярый оппонент Иммануила Канта (1724-1804) [21, 22] и как автор понятия «досократовская философия» $[2,12,13]$, производным от которого стало понятие «досократики», введенное в конце XIX века Германом Дильсом (18481922). Последнее весьма примечательно, ведь И.А. Эберхард выделил в истории древнегреческой философии такую фигуру, которая смогла стать своеобразным водоразделом между теми древнегреческими философами, которых принято считать архаическими (например, Фалес или Пифагор), и теми древнегреческими философами, которых принято считать классическими (например, Платон или Аристотель). Этой фигурой стал Сократ. Кроме того, И.А. Эберхард использовал фигуру Сократа в качестве аргумента в пользу учения об Apokatastasis panton. Как можно видеть, И.А. Эберхард живо интересовался Сократом. Это позволяет мне предложить провести анализ образа Сократа, представленный в философии Иоганна Августа Эберхарда. Такой анализ и есть целью предлагаемого исследования.

И.А. Эберхард обращается к фигуре Сократа в двух своих работах: «Новая апология Сократа, или Исследование учения о благе у язычников», 1772-1778 и «Всеобщая история философии», 1788. И обращается он к этой фигуре не случайно, а поддавшись интеллектуальной моде на философа Сократа в XVIII веке.

Как считает ряд исследователей [3, 14, 23, 24, 25], XVIII век был «веком Сократа». Так как интеллектуалы по всей Европе стремились 
связать свои интеллектуальные усилия с Сократом, Сократа превратили в фигуру Нового времени. Причем здесь возникли две линии интерпретации фигуры Сократа: одни, такие как Жак-Луи Давид и Перси Биши Шелли, сравнивали Сократа с Иисусом Христом; другие, такие как Вольтер, Дени Дидро и Жан-Жак Руссо, пытались из Сократа сделать образец рациональности. По всей видимости, эту моду на философа Сократа установил французский философ Петр Рамус (Пьер де ла Рамэ, 1515-1572), который использовал фигуру Сократа в своих нападках на схоластику и в своей антиаристотелевской полемике. В одном месте своей «Диалектики» П. Рамус формулирует свой бунт против Аристотеля: «Что предупреждает меня от сократизации и, опуская авторитет Аристотеля, стремления обнаружить, истинно и подходяще ли учение диалектики?» [19, с.151]. Аккуратность самохарактеристики П. Рамуса и законность его отрицания аристотелизма постоянно подвергались сомнению схоластами. Тем не менее, полемическое использование Сократа П. Рамусом - его использование как модели живого интеллектуального опыта - помогло установить традицию представления Сократа как оппозиционера.

Именно в таком образе Сократа было заинтересовано Просвещение, которое отталкивалось от представления, сформированного Пьером Бейлем (1647-1706) и деистами, о том, что мораль возможна отдельно от христианства (то есть, что нравственные поступки и нравственные достоинства независимы от религиозного убеждения). Сократ был тем философом, который своей честностью мог бы воплощать собой идеального человека, независимого от христианской веры. Никто не мог всерьез отрицать, что Сократ олицетворяет определенные добродетели, такие как воздержанность, моральная чистота и преданность идеалам справедливости даже перед нависшей угрозой смерти. Эти добродетели в целом рассматривались как возможные для людей и до христианского откровения и даже без христианского откровения.

В эпоху Просвещения образ Сократа стал оружием теологического рационализма, принятого в немецкоязычной историографии общего названия для различных теологических версий рационализма (естественная теология, деизм, супранатурализм, неология) [20]. Это означает, что в споре между светской философией и христианской религией по вопросу автономии разума и возможности ее самообоснования, философы Просвещения приводят Сократа в качестве главного свидетеля. Так, например, Энтони Коллинз (1676-1729) в своей книге «Рассуждение о вольнодумии», 1713 [6] изображает Сократа как образцового вольнодумца, которого преследуют священники. Джон Гилберт 
Купер (1723-1769) характеризует Сократа как воина за чистую естественную религию в «Жизни Сократа», 1749 [7].

Одной из самых популярных в эпоху Просвещения была книга Франсуа Шарпентье (1620-1702) «Жизнь Сократа», 1650 [5], в которой Сократ изображен как человек мира без ярко выраженной борьбы с христианством. Здесь важно отметить, что Ф.Шарпентье больше интересовали не философские взгляды Сократа, а детали его интимной жизни. Особенно много внимания Ф. Шарпентье уделяет отношениям Сократа с его двумя женами-Ксантиппой и Мирто. Например, Ф.Шарпентье показывает реакцию Ксантиппы на вторую жену Сократа: Ксантиппа опрокидывает на Сократа содержимое ночного горшка и переворачивает обеденный стол в припадке гнева. Скорее всего, именно из-за такого рода деталей «Жизнь Сократа» $\Phi$.Шарпентье пользовалась в те времена бешеной популярностью. $\Phi$.Шарпентье оказался крайне значим для дискуссий о Сократе в XVIII веке, так как он включил перевод «Воспоминаний» Ксенофонта в свою книгу и, таким образом, поспособствовал популяризации текста Ксенофонта. В 1693 году книга [4] Ф. Шарпентье была переведена на немецкий язык немецким философом и юристом Христианом Томазием (1655-1728).

Несмотря на резкое различие между точками зрения Дж.Г. Купера и Ф. Шарпентье, обе книги о Сократе стали главными источниками для Иоганна Георга Гаманна (1730-1788) и Моисея Мендельсона (17291786), авторов двух самых известных и важных книг о Сократе в XVIII веке. В 1759 году И.Г. Гаманн публикует свои «Воспоминания о Сократе» [11], текст, который оказал сильное влияние на движение «Штурм и Натиск», в том числе и на таких авторов, как Иоганн Готфрид Гердер (1744-1803) и Фридрих Генрих Якоби (1743-1819), а через них - на Иоганна Вольфганга фон Гете (1749-1832). Последний даже некоторое время планировал написать драму о Сократе, но затем начал работу над «Фаустом» [3, с. 301]. В 1767 году М. Мендельсон публикует книгу «Федон, или О бессмертии души» [18].

Именно под влиянием И.Г. Гаманна и М. Мендельсона И.А. Эберхард обращается к фигуре Сократа в своей «Новой апологии Сократа» 1772 года. Однако, несмотря на то, что работа Эберхарда называется «Новая апология Сократа», сама книга не о Сократе. В действительности первый том книги «Новая апология Сократа» был реакцией Эберхарда на роман французского историка и писателя Жана Франсуа де Мармонтеля (1723-1799) «Велизарий» (Belisaire, 1767). В пятнадцатой главе романа слепой бывший римский полководец Велизарий рас- 
крывает свое учение о добродетели в дискуссии с императором Юстинианом и молодым Тиберием: «Хороший человек связан с Богом. Он уверен, что Бог любит его» $[17$, с. 175]. На основании этой мысли Велизарий приходит к двум вещам: 1) язычники тоже попадают на Небеса; 2) государство имеет право только принимать решения по поводу тех вещей, которые безобидны и полезны для общего блага, но не по поводу того, истинно или ложно то, чего обязан придерживаться отдельный верующий $[17$, с. $180-181,187]$. «Каждый человек сам отвечает за свою душу. Она также рядом с ним и полностью с ним наедине, чтобы сделать выбор, который вовлекает его в вечное проклятие или спасение» [17, с. 190].

Через несколько дней после публикации в феврале 1767 года роман «Велизарий» был запрещен цензурой, но распространению этого текста уже ничто не могло помешать. Вольтер выступил с защитой Мармонтеля, что принесло роману известность во Франции и по всей Европе. В том же году появился немецкий перевод романа «Велизарий», затем последовали его переиздания и пиратские копии.

Роман «Велизарий» прекрасно вписался в разворачивавшуюся в то время в немецком Просвещении дискуссию по поводу учения об Apokatastasis panton (буквально с древнегреческого 'восстановление (возвращение) всех'), которое зачастую переводится на немецкий язык как Wiederbringung Aller 'возвращение всех' или как Allversöhnung 'примирение всех'. Учение об Apokatastasis, а именно: о том, что по Воле Бога спасения могут, в конечном счете, достичь все, даже самый последний грешник, - поддерживалось многими Отцами Церкви, в том числе Оригеном. Церковь признала это учение ересью на Константинопольском Синоде 543 года и Пятом Вселенском Соборе 553 года. Наиболее существенным аргументом против этого учения было то, что оно противоречит доктрине вечного наказания в аду [16].

Однако попытки полностью искоренить учение об Apokatastasis так и не увенчались успехом. Лютеранская теология позволила вернуться к этому вопросу в XVIII столетии. Разработка учения об Apokatastasis пошла по двум направлениям. Сторонники первого направления, вдохновленные мессианскими и хилиастическими идеями, поддержали учение об Apokatastasis в эмфатическом смысле этого слова. Сторонники второго направления выдумали временные сроки для наказания в аду, которое призвано было исправлять грешника для вечного блаженства. В контексте сказанного и был написан И.А. Эберхардом в 1772 году первый том «Новой апологии Сократа».

Появление первого тома «Новой апологии Сократа» позволило Гот- 
хольду Лессингу (1729-1781) опубликовать работу «Лейбниц о вечном наказании» [15] в январе 1773 года, в которой он защищал Готфрида Лейбница (1646-1716) от упрека И.А. Эберхарда в том, что Г. Лейбниц придерживался ортодоксальности, философски оправдывая свою поддержку доктрины вечного наказания в аду. В поддержку своей точки зрения Г. Лессинг опубликовал текст Эрнста Зонера (1573-1612) «Demonstratio theologica et philosophica, quod aeterna impiorum supplicia non arguant Dei justitiam sed injustititiam» ('Теологическая и философская демонстрация того, что вечное неверующих свидетельствует не о справедливости, а скорее о несправедливости Бога'). Здесь важно понять, как связаны Э. Зонер и Г. Лейбниц между собой. В своей «Теодицее» Г. Лейбниц упоминает редкую книгу Э. Зонера, в которой делалась попытка показать, что вечное проклятие является ложным учением, потому что ни один конечный грех не может быть соразмерным бесконечному наказанию. Г. Лейбниц представлял себя как человека, который знает, как ответить Э. Зонеру так, чтобы догма была спасена. Ответ был таков: проклятые продолжают грешить в аду, это и образует вечное наказание из конечного греха [1, с. 312]. Г. Лейбниц собирался переиздать книгу Э. Зонера со своим критическим предисловием, однако этого не произошло по каким-то причинам. Саму же затею Г. Лейбница впоследствии реализовал Г. Лессинг.

И.А. Эберхард ответил на критику Г. Лессинга вторым томом «Новой апологии Сократа» в 1776 году. В этом томе И.А. Эберхард высказывает мысль, что Г. Лейбниц, как и многие античные философы, придерживался двух доктрин: экзотерической популярной и эзотерической тайной. K этой мысли И.А. Эберхард приходит на основании мнения, что оптимизм Г. Лейбница не мог быть совместим с доктриной вечного наказания проклятых.

Ответ Г. Лейбница на книгу Э. Зонера можно рассматривать, как то, что относится к экзотерической доктрине Г. Лейбница. Однако остается еще эзотерическая доктрина Г. Лейбница. И.А. Эберхард полагал, что реальная вера Г. Лейбница заключалась в том, что мир постоянно увеличивается в совершенстве, асимптотически возвышаясь к состоянию абсолютного совершенства, как предполагал Г. Лейбниц в письме к Луи Бурже (1678-1742) в 1714 году. Наличие двух противоречащих доктрин Г. Лейбница И.А. Эберхард объясняет стремлением Лейбница получить одобрение своей философии, поэтому Лейбниц пытался представлять свои доктрины в выгодном свете для всех спорящих сторон. «Он брал их догмы как предположения и придавал им приемлемый смысл, приводя их в соответствие со своей системой, 
не обязывая себя» $[10$, с. 415]. И.А. Эберхард отмечает, что Г. Лейбниц часто предлагал свою философию в качестве решения чьей-то проблемы: он показал Варфоломею Дес Боссесу (1648-1738), например, как объяснить пресуществление на монадологических основах, несмотря на то, что сам Г. Лейбниц был сторонником консубстантиации (соосуществления) [10, с. 492].

Здесь меня больше интересует первый том «Новой апологии Сократа» И.А. Эберхарда. С целью доказать, что учение о проклятии язычников абсурдно, И.А. Эберхард в первой части книги ставит два вопроса: «Является ли исключением такое большое число людей, пригодных для мудрости и совершенства Бога, и основания, на которых строится эта доктрина, столь же устойчивы, как они пытаются доказать?» [9, с. 48].

Отвечая на первый вопрос, И.А. Эберхард исходит из двух petitiones principii. Первый petitio principii заключается в том, что Бог сущностно совершенен. С позиции этого принципа относительно природы Бога для Эберхарда становится несомненным, что грехи не могут быть приписаны тому, кто сам их не совершал, и, следовательно, доктрина первородного греха недействительна. Второй petitio principii состоит в том, что Бог не может наложить на грешника наказание, которое нельзя облегчить или отменить с помощью самоисправления. Наказания, так как они совершенны, должны «применяться даже к лучшему из страдальцев, и, следовательно, как только исправление имеет место, они должны быть ослаблены» [9, с. 114]. И.А. Эберхард отвечает на второй вопрос, исследуя доктрины, которые поддерживают вечное проклятие язычников, и он приписывает им недостатки в толковании Библии.

Во второй части книги И.А. Эберхард рассуждает в защиту нравственного поведения нехристиан. С одной стороны, он показывает через антропологические и философские причины, что язычники способны на нравственно хорошее поведение. С другой стороны, он приводит доказательства на основании этнологических и исторических источников, которые подтверждают подлинную добродетельность их поведения. Главным аргументом выступает жизнь и учение язычника Сократа. В итоге следствием его рассуждения является то, что «Бог не может отвергать добродетельные души язычников, еще меньше он может их проклинать навечно» [9, с. 434].

Таким образом, в своей «Новой апологии Сократа» И.А. Эберхард использует Сократа как аргумент в пользу учения об Apokatastasis panton. В учебнике «Всеобщая история философии» он уже старается 
рассмотреть подлинный исторический образ Сократа и раскрыть его философию. Вот что Әберхард сообщает о взглядах Сократа:

\begin{abstract}
Основное содержание сократовской философии заключалось в популярной теологии и общей естественной этике, и по причине этого она отличалась от философии всех его предшественников и последователей. В теологии он имел дело только с исследованием конечных причин, из которых нам известно, как нам действовать, и утверждал, что их исследование полезно, в силу того что это исследование конечных причин. Он связывал эту популярную теологию с естественной этикой тем, что учил, что лучшее и богоугодное богослужение заключается в исполнении перед самим собой обязанностей, состоящих в общении и домашних и гражданских обязанностях, потому что благодаря исполнению всех этих обязанностей лучше всего достигается конечная цель высшего существа, которая заключается всецело в совершенстве и блаженстве. Этому высшему существу подчиняются высшие благодетельные духи, даймоны, благодаря которым бог управляет миром и святыми душами, не ограничивая их чувственность, чтобы они были внимательны к едва заметным знакам бытия, подаваемым по случаю [8, c. 109-110].
\end{abstract}

У Сократа, оказывается, есть даймон, который дает ему советы, в том числе, как познавать мир с помощью таких способов познания, как майевтика и ирония. Эти способы познания позволяют Сократу противостоять софистам и их «всезнайству» $[8$, с. 108].

Кроме того, он [= Сократ] учил определенным образом о точной связи между всеми добродетелями и всех добродетелей с благом человеческого общества, к которому, прежде всего, принадлежит патриот $[8$, c. 110].

Это было еще одним аргументом Сократа против софистов: их «риторические и политические занятия не согласовывались с основными принципами общей этики» [8, с. 108].

Таким образом, И.А. Эберхард рисует образ Сократа как религиозного и морального (этического) философа. Этот образ позволяет И.А. Эберхарду сделать философию Сократа критерием, по которому можно разделить историю древнегреческой «научной» философии на два основных периода - «досократовскую философию» и «сократовскую философию».

Резюмируя сказанное выше, следует отметить, что Иоганн Август Эберхард рисует образ Сократа как религиозного и морального (этического) философа для подкрепления своего аргумента в пользу учения об Apokatastasis panton. K такому образу Сократа И.А. Эберхард приходит под влиянием интеллектуальной моды на Сократа в XVIII 
веке, особенно усиленной работами старших коллег Эберхарда: «Воспоминаниями о Сократе» Иоганна Георга Гаманна и «Федоном, или О бессмертии души» Моисея Мендельсона. Нарисованный образ Сократа позволяет И.А. Эберхарду сделать философию Сократа критерием, в соответствии с которым можно разделить историю древнегреческой «научной» философии на два основных периода - «досократовскую философию» и «сократовскую философию».

\section{Литература}

[1] Лейбнии Г.В. Опыты теодицеи о благости Божией, свободе человека и начале зла // Лейбниц Г.В. Сочинения в 4 тт. - Т. 4. Москва: Мысль, 1989. - С. 49-401.

[2] Paйхерт K.В. «Досократовская философия» Иоганна Августа Эберхарда // Sententiae. - 2012. — № 1 (XXVI). - C. 110-120.

[3] Böhm B. Sokrates im 18. Jahrhundert. - Neumünster: Wachholtz, 1966.

[4] Charpentier F. Das Ebenbild eines wahren und ohne pedantischen Philosophie, oder das Leben Sokrates. Ins Deutsche übersetzt Von Christian Thomas. - Halle : Salfeld, 1693.

[5] Charpentier F. Les Choses mémorables de Socrate, Ouvrage de Xenophon traduit du Grec en Fiança es. Avec La Vie de Socrates, Nouvellement composée et recueillie des plus célébrés Auteurs de l'antiquité. - Paris : Augustin Courbö, 1650.

[6] Collins A. A Discourse of Free-thinking, Occasion'd by the Rise and Growth of a Sect Call'd Free-Thinkers. - London, 1713.

[7] Cooper J.G. The Life of Socrates. - London: R. Dodsley, 1750.

[8] Eberhard J.A. Allgemeine Geschichte der Philosophie zum Gebrauch Akademischer Vorlesungen. - Halle: Hemmerdeshen Buchhandlung, 1788 .

[9] Eberhard J.A. Neue Apologie des Sokrates oder Untersuchung der Lehre von der Seligkeit der Heiden. - Berlin und Stettin bei Friedrich Nicolai. - Band 1. - 1776. 
[10] Eberhard J.A. Neue Apologie des Sokrates oder Untersuchung der Lehre von der Seligkeit der Heiden. - Berlin und Stettin bei Friedrich Nicolai. - Band 2. - 1778 .

[11] Hamann J.G. Sokratische Denkwürdigkeiten // Hamann's Schriften. - Zweiter Theil. - Berlin: G. Reimer, 1821. - S. 1-51.

[12] Lafrance $Y$., Paquet L. Les présocratiques: Bibliographie analytique, (1450-1879). - Quebec: Bellarmin, 1995.

[13] Laks A. «Philosophes Presocratiques»: Remarques sur la construction d'une catégorie de l'historiographie philosophique // Qu'est-ce que la philosophie présocratique? What is Presocratic Philosophy? / Édité par André Laks, Claire Louguet. - Lille: Presses Universitaires du Septentrion, 2000. - P. 17-38.

[14] Leonard M. Greeks, Jews, and the Enlightenment: Moses Mendelssohn's Socrates // Cultural Critique. - 2010. - № 74. P. 183-199.

[15] Lessing G.E. Leibnitz von den ewigen Strafen // Lessing G.E. Werke.-Bd.7. - Donaueschingen im Verlage deutscher Klassiker, 1822. - S. 131-170.

[16] Lochman J.M. Apokatastasis // Evangelisches Kirchenlexicon.Bd. 1. - Göttingen, 1986. - Col. 202-203.

[17] Marmontel de J.-F. Belisaire / Édition établie, présenté et annotée par Robert Granderoute. - Paris: Société des Textes français modernes, 1994.

[18] Mendelssohn M. Phädon, oder über die Unsterblichkeit der Seele.Berlin und Stettin bei Friedrich Nicolai, 1776.

[19] Ramus $P$. Scholae in tres primas liberales artes: videlicet 1 . grammaticae 2. rhetoricae, quae olim quaestiones brutinae 3 . dialecticae, quae olim animadversiones in organum Aristotelis (1581). - Frankfurt a. M. : Minerva Press, 1965.

[20] Rosenberg H. Theologischer Rationalismus und vormärzlicher Vulgarliberalismus // Historische Zeitschrift. - Bd.141. - 1930. № 3. - S. 497-541. 
[21] Senderowicz Y. Facing the Bounds of Tradition: Kant's Controversy with the Philosophisches Magazin // Science in Context. - 2008. Volume: 11 . - № 2. - P. 205-228.

[22] The Kant - Eberhard Controversy: an English translation, together with supplementary materials and a historical-analytic introduction of Immanuel Kant's on a discovery according to which any new critique of pure reason has been made superfluous... by Henry E. Allison. Baltimore: The Johns Hopkins University Press, 1973.

[23] Trapp M. Socrates in the Nineteenth and Twentieth Centuries. Aldershot and Burlington, VT: Ashgate, 2007.

[24] Trousson $R$. Socrate devant Voltaire, Diderot et Rousseau: La conscience en face du mythe. - Paris : Minard, 1967.

[25] Vieillard-Baron J.-L. Platon et l'Idéalisme Allemand 1770-1830.Paris : Beauchesne, 1979.

Надійшла до редакиї 26 квітня 2017 р. 


\title{
Анотація
}

Райхерт К.В. Образ Сократа в філософії Йогана Августа Ебергарда

У статті показано, в який спосіб німецький філософ, теолог і класичний філолог Йоган Август Ебергард зображує Сократа як релігійного і морального філософа для підсилення свого аргументу на користь вчення про Apokatastasis panton. Створений образ Сократа дозволяє Ебергарду зробити філософію Сократа критерієм, за яким можна поділити історію давньогрецької «наукової» філософії на два періоди - «досократівську філософію» та «сократівську філософію».

Ключові слова: досократики, історія філософії, Сократ, теологія, Apokatastasis panton.

\begin{abstract}
Rayhert K.W. The Image of Socrates in Johann August Eberhard's Philosophy

The study demonstrates how German philosopher, theologian and classicist Johann August Eberhard portrayed Socrates as a religious and moral philosopher to prove the doctrine of Apokatastasis panton. Such an image of Socrates allowed Eberhard to consider Socrates' philosophy a criterion for a division of Ancient Greek philosophy into Pre-Socratic and Socratic stages.

Keywords: Presocratics, history of philosophy, Socrates, theology, Apokatastasis panton.
\end{abstract}

\section{References}

(1) Leibniz G.W. Experiences of the theodicy about the goodness of God, human freedom and the beginning of evil // Leibniz G.W. Sochinenija v 4 tt. - T. 4. - Moskva : Mysl, 1989. - C. 49-401.

(2) Rajhert K.V. «Dosokratovskaja filosofija» Ioganna Avgusta Eberharda // Sententiae. - 2012. - No 1 (XXVI). - C. 110-120.

(3) Bohm B. Sokrates im 18. Jahrhundert. - Neumunster : Wachholtz, 1966. 
(4) Charpentier F. Das Ebenbild eines wahren und ohne pedantischen Philosophie, oder das Leben Sokrates. Ins Deutsche u bersetzt Von Christian Thomas. - Halle : Salfeld, 1693.

(5) Charpentier F. Les Choses memorables de Socrate, Ouvrage de Xenophon traduit du Grec en Fianca es. Avec La Vie de Socrates, Nouvellement composee et recueillie des plus celebres Auteurs de l'antiquite. Paris : Augustin Courbo, 1650.

(6) Collins A. A Discourse of Free-thinking, Occasion'd by the Rise and Growth of a Sect Call'd Free-Thinkers. - London, 1713.

(7) Cooper J.G. The Life of Socrates. - London : R. Dodsley, 1750.

(8) Eberhard J.A. Allgemeine Geschichte der Philosophie zum Gebrauch Akademischer Vorlesungen. - Halle : Hemmerdeshen Buchhandlung, 1788 .

(9) Eberhard J.A. Neue Apologie des Sokrates oder Untersuchung der Lehre von der Seligkeit der Heiden. - Berlin und Stettin bei Friedrich Nicolai. - Band 1. - 1776.

(10) Eberhard J.A. Neue Apologie des Sokrates oder Untersuchung der Lehre von der Seligkeit der Heiden. - Berlin und Stettin bei Friedrich Nicolai. - Band 2. - 1778.

(11) Hamann J.G. Sokratische Denkwurdigkeiten // Hamann's Schriften. - Zweiter Theil. - Berlin : G. Reimer, 1821. - S. 1-51.

(12) Lafrance Y., Paquet L. Les presocratiques: Bibliographie analytique, (1450-1879). - Quebec : Bellarmin, 1995.

(13) Laks A. «Philosophes Presocratiques»: Remarques sur la construction d'une categorie de l'historiographie philosophique // Qu'est-ce que la e philosophie presocratique? What is Presocratic Philosophy? / Editpar Andre Laks, Claire Louguet. - Lille : Presses Universitaires du Septentrion, 2000. - P. 17-38.

(14) Leonard M. Greeks, Jews, and the Enlightenment: Moses Mendelssohn's Socrates // Cultural Critique. - 2010. - No 74. - P. 183-199.

(15) Lessing G.E. Leibnitz von den ewigen Strafen // Lessing G.E. Werke. - Bd. 7. - Donaueschingen im Verlage deutscher Klassiker, 1822. S. 131-170. 
(16) Lochman J.M. Apokatastasis // Evangelisches Kirchenlexicon. - Bd. 1. - Gottingen, 1986. - Col. 202-203.

(17) Marmontel de J.-F. Belisaire / Editionetablie, presente et annotee par Robert Granderoute. - Paris : Societe des Textes francais modernes, 1994.

(18) Mendelssohn M. Phadon, oder u ber die Unsterblichkeit der Seele. - Berlin und Stettin bei Friedrich Nicolai, 1776.

(19) Ramus P. Scholae in tres primas liberales artes: videlicet 1. grammati cae 2. rhetoricae, quae olim quaestiones brutinae 3. dialecticae, quae olim animadversiones in organum Aristotelis (1581). - Frankfurt a. M. : Minerva Press, 1965.

(20) Rosenberg H. Theologischer Rationalismus und vormarzlicher Vulgar liberalismus // Historische Zeitschrift. - Bd. 141. - 1930. - No 3. - S. 497-541.

(21) Senderowicz Y. Facing the Bounds of Tradition: Kant's Controversy with the Philosophisches Magazin // Science in Context. - 2008. Volume: 11. - No 2. - P. 205-228.

(22) The Kant - Eberhard Controversy: an English translation, together with supplementary materials and a historical-analytic introduction of Immanuel Kant's on a discovery according to which any new critique of pure reason has been made superfluous. . . by Henry E. Allison. - Baltimore : The Johns Hopkins University Press, 1973.

(23) Trapp M. Socrates in the Nineteenth and Twentieth Centuries. Aldershot and Burlington, VT : Ashgate, 2007.

(24) Trousson R. Socrate devant Voltaire, Diderot et Rousseau: La conscience en face du mythe. - Paris : Minard, 1967.

(25) Vieillard-Baron J.-L. Platon et l'Idealisme Allemand 1770-1830. Paris : Beauchesne, 1979. 